\title{
PENENTUAN KADAR FLAVONOID EKSTRAK ETANOL 70\% KULITBAWANG MERAH (Allium cepa L.) DENGAN METODE MASERASI DAN MAE (Microwave Assisted Extraction)
}

\author{
Lusi Agus Setiani, Bina Lohita Sari, Lusi Indriani, Jupersio
}

Program Studi Farmasi, FMIPA, Universitas Pakuan Bogor

Email: lusi.setiani@yahoo.com

\begin{abstract}
ABSTRAK
Kulit bawang merah mengandung senyawa flavonoid, polifenol, saponin, terpenoid dan alkaloid. Golongan flavonoid yang terdapat pada kulit bawang merah adalah flavonol yang berkhasiat sebagai antioksidan kuat serta diketahui dapat mengurangi risiko tumor, kanker, penyakit jantung, stroke, bronchitis, asma dan anti peradangan. Penelitian ini bertujuan untuk menentukan dan membandingkan kadar flavonoid ekstrak etanol 70\% kulit bawang merah menggunakan metode maserasi dan MAE (Microwave Assited Extraction). Metode ekstraksi maserasi dilakukan pada suhu kamar dan MAE pada suhu $80^{\circ} \mathrm{C}$. Kadar flavonoid diukur menggunakan alat spektrofotometri UV-VIS dengan reagen $\mathrm{AlCl}_{3}$. Senyawa standar flavonoid yang digunakan adalah kuersetin. Kadar flavonoid yang didapatkan dengan metode maserasi adalah sebesar 14,92\% dan kadar flavonoid yang didapatkan dengan metode MAE adalah sebesar 17,18\%. Dari data ini dapat disimpulkan bahwa metode MAE (Microwave Assited Extraction) lebih efektif digunakan untuk mengekstrak flavonoid dari kulit bawang merah dibandingkan dengan metode maserasi.
\end{abstract}

Kata Kunci: Kulit bawang merah, maserasi, MAE, flavonoid

\section{DETERMINATION OF FLAVONOID CONTENT IN ONION SKIN (Allium cepa L.) $70 \%$ ETHANOL EXTRACT USING MACERATION AND MICROWAVE ASSISTED EXTRACTION METHOD}

\begin{abstract}
The onion skin contains flavonoid, polyphenols, saponins, terpenoids and alkaloids compounds. Among the flavonoid group found in the onion skin is flavonol. The flavonol has strong antioxidant and anti-inflammation activites, and proved to reduce the risk of tumors, cancer, heart disease, stroke, bronchitis and asthma. This study was aimed to determine the level of flavonoid in the $70 \%$ ethanol extract of onion skin. The extraction proses was performed using maceration and MAE (Microwave Assited Extraction) methods. The maceration method was performed at room temperature and the MAE at $80^{\circ} \mathrm{C}$. The flavonoid level was measured using spectrophotomether uv-vis machine with $\mathrm{AlCl}_{3}$ as a reagen. Quercetin was used as a standard compound to detect the flavonoid content. The results show that the flavonoid level in the extract of onion skin obtained from maseration and MAE methods were $14,92 \%$ and 17,18\% respectively. It can be concluded that the MAE methods was more effective to extract flavonoid from onion skin compare to the maceration method.
\end{abstract}

Keywords: Onion skin, maceration, MAE, flavonoids 


\section{PENDAHULUAN}

Bawang merah merupakan komoditi hortikultura yang tergolong sayuran rempah. Sayuran rempah ini banyak dibutuhkan terutama sebagai pelengkap bumbu masakan untuk menambah citarasa dan kenikmatan makanan (Rahayu dan Nur 2004). Bawang merah juga mengandung flavonoid, asam fenol, sterol, saponin, pektin, serta kaya vitamin B1, B2 dan C (Adi, 2007). Selain itu, bawang merah juga memiliki kandungan senyawa seperti rutin dan kuersetin yang diyakini dapat digunakan sebagai antiinflamasi (Filomena et al., 2007). Menurut Utami dan Mardiana (2013), flavonoid memiliki manfaat antara lain untuk melindungi struktur sel, meningkatkan efektifitas vitamin $\mathrm{C}$, antiinflamasi, mencegah keropos tulang dan sebagai antibiotik. Hasil penelitian sebelumnya menunjukan bahwa gel yang dibuat dari ekstrak umbi bawang bawang merah mengandung senyawa flavnoid yang berpotensi sebagai antioksidan yang dapat mencegah berkembangnya radikal bebas di dalam tubuh dan dapat memperbaiki sel-sel tubuh yang rusak (Soebagio et al., 2007).

Kandungan senyawa kimia aktif selain terdapat pada umbi bawang merah, terdapat juga pada kulitnya. Dari hasil penelitian Rahayu dan Nur (2015) diketahui bahwa ekstrak kulit bawang merah pada fraksi air mengandung flavonoid, polifenol, saponin, terpenoid dan alkaloid, pada fraksi etil asetat mengandung flavonoid, polifenol dan alkaloid, pada fraksi n-heksana mengandung saponin, steroid dan terpenoid. Senyawa flavonoid yang terkandung pada ekstrak kulit bawang merah fraksi etil asetat adalah dari golongan flavonol.

Senyawa flavonoid adalah golongan senyawa yang tidak tahan panas dan mudah teroksidasi pada suhu tinggi (Rompas, 2012). Berdasarkan hasil penelitian Umar (2008) tentang optimasi ekstraksi flavonoid pada daun jati belanda dengan pelarut etanol konsentrasi 50,70 dan 90\%, diperoleh kadar flavonol tertinggi pada konsentrasi etanol $70 \%$ dengan perbandingan bahan baku:pelarut adalah 1:10. Dengan adanya perkembangan metode ekstraksi dari konvensional kearah modern, diharapkan akan didapatkan hasil ekstraksi dengan kadar yang optimal. Salah satu metode ekstraksi konvensional yang umum digunakan adalah metode maserasi, yaitu dengan penyarian yang sederhana. Maserasi dilakukan dengan cara merendam serbuk simplisia dalam cairan penyari. Cairan penyari akan menembus dinding sel simplisia dan masuk ke dalam rongga sel yang mengandung senyawa aktif. Senyawa aktif akan larut karena adanya perbedaan konsentrasi antara larutan zat aktif di dalam sel dengan yang di luar sel, maka larutan yang pekat akan tertarik keluar sel (Depkes RI, 1986). Metoda ekstraksi modern salah satunya adalah Microwave Assisted Extraction (MAE). Metoda ekstraksi ini memanfaatkan radiasi gelombang mikro untuk mempercepat ekstraksi selektif melalui pemanasan pelarut secara cepat dan efisien karena gelombang elektromagnetiknya akan menembus dinding sel simplisia dan mengeksitasi molekul air serta lemak secara merata (tidak hanya permukaannya saja). Gelombang elektomagnetik pada frekuensi $2.500 \mathrm{MHz}(2,5 \mathrm{GHz})$ ini diserap oleh air, lemak dan gula kemudian mengeksitasi atom-atom didalam sel sehingga menghasilkan panas. Karena panas dihasilkan dari dalam sel itu sendiri, maka metoda ekstraksi MAE tidak memerlukan konduksi panas seperti di oven biasa. Dengan mekanisme seperti ini, maka proses ekstraksi karena itulah dilakukan sangat cepat tanpa merusak zat aktif yang ada didalam sel simplisia (Jain et al., 2009). Penelitian ini dilakukan untuk membandingkan 2 metode ekstraksi yakni maserasi dan MAE (Microwave Assited 
Extraction) menggunakan pelarut etanol $70 \%$ dengan harapan diperoleh kadar flavonoid tertinggi dari ekstrak kulit bawang merah. Kadar flavonoid pada ekstrak kulit bawang merah diukur dengan metode $\mathrm{AlCl}_{3}$ menggunakan alat spektrofotometer UV-VIS.

\section{METODE PENELITIAN}

\section{Waktu dan Tempat Penelitian}

Penelitian ini telah dilaksanakan pada bulan Juli sampai Agustus 2017, bertempat di Laboratorium Farmasi Fakultas Matematika dan Ilmu Pengetahuan Alam Universitas Pakuan.

\section{Alat dan Bahan}

Alat-alat yang digunakan dalam penelitian ini adalah timbangan analitik (And®), oven, grinder (Phillips), ayakan mesh 40, tanur (Ney®), moisture balance (AND MX 50®, sop watch, vacuum evaporator, microwave (Phillips), dan alatalat gelas.

Bahan-bahan yang digunakan dalam penelitian ini adalah kulit bawang merah, akuades, etanol $70 \%$, asam sulfat $\left(\mathrm{H}_{2} \mathrm{SO}_{4}\right)$ pekat dan $2 \mathrm{M}$, kloroform, asam klorida $(\mathrm{HCl})$ pekat, amil alkohol, asam asetat anhidrat, $\mathrm{FeCl}_{3} 1 \%$, reagen pewarnaan (Dragedorff, Mayer dan Wagner). Semua zat kimia yang digunakan memiliki kualifikasi PA (pro alasis) dari SigmaAldrich.

\section{Pengumpulan Bahan Baku}

Bahan yang digunakan kulit bawang merah yang diperoleh dari Pasar TU Kemang Daerah Bogor, yang berasal dari daerah Brebes Jawa Tengah.

\section{Pembuatan Serbuk Simplisia}

Kulit bawang merah dibersihkan dari pengotor yang menempel dengan air mengalir sampai bersih. Pengeringan simplisia dilakukan dengan cara di jemur di bawah sinar matahari dan bagian atas simplisia dilapisi dengan kain hitam, sehingga tidak terkena paparan cahaya matahari langsung. Simplisia yang telah kering ditimbang kemudian di grinder sampai menjadi serbuk. Serbuk yang diperoleh diayak dengan mesh no. 40 lalu ditimbang.

\section{Uji Kadar dan Kadar Abu Simplisia dan Ekstrak}

Penetapan kadar air simplisia dilakukan dengan menggunakan metode gravimetri. Kadar abu ditetapkan dengan memanaskan simplisia pada suhu $\pm 600^{\circ} \mathrm{C}$ dimana senyawa organik dan turunannya terdekstruksi dan menguap hingga tersisa unsur anorganik.

\section{Ekstraksi Kulit Bawang Merah Metode Maserasi}

Ekstraksi dilakukan secara duplo menggunakan $500 \mathrm{~mL}$ (1:10) pelarut etanol 70\%. Dimasukan 50 g serbuk kering simplisia ke dalam maserator, lalu ditambah $500 \mathrm{~mL}$ pelarut etanol $70 \%$. Larutan dikocok selama 1 jam kemudian didiamkan selama kurang lebih 1 jam, dikocok lagi selama 15 menit dan didiamkan selama 1 jam. Proses ini diulangi sampai 5 kali, larutan kemudian diamkan selama 1 hari. Residu dan filtrat kemudian dipisahkan, residu diremaserasi sebanyak 2 kali dengan dengan $100 \mathrm{~mL}$ alkohol $70 \%$, filtratnya dikumpulkan kemudian diuapkan dengan rotary evaporator sehingga diperoleh ekstrak kental (Kemenkes, 2013). Ekstrak kemudian dikeringkan dengan vaccum dryer dan dihitung rendemennya.

\section{Ekstraksi Kulit Bawang Merah Metode MAE (Microwave assisted Ekstraction)}

Ekstraksi metoda MAE dilakukan secara duplo berdasarkan referensi penelitian sebelumnya (Quan, et. al., 2006). Sebanyak 50 g serbuk kulit bawang merah dimasukkan kedalam erlenmeyer dan ditambahkan $500 \mathrm{~mL}(1: 10)$ etanol $70 \%$ kemudian dimasukkan kedalam 
microwave dengan daya 800 watt selama 6 menit. Larutan diradiasi dalam microwave oven secara berkala (radiasi 1 menit dan 2 menit dimatikan) untuk menjaga suhu tidak lebih dari $80^{\circ} \mathrm{C}$. Larutan kemudian didiamkan pada suhu kamar, disaring dan filtrat diuapkan dengan Rotary evaporator hingga menjadi ekstrak kental. Ekstrak kemudian dikeringkan dengan vaccum dryer dan dihitung rendemennya.

\section{Analisis Fitokimia}

\section{Uji Flavonoid}

Ekstrak sebanyak 0,5 gram dilarutkan dalam $5 \mathrm{~mL}$ etanol $95 \%$. Larutan sampel diambil $2 \mathrm{~mL}$, ditambahkan 0,1 gram serbuk $\mathrm{Mg}$ dan 10 tetes HCL pekat dari sisi tabung kemudian dikocok perlahan-lahan. Warna merah atau jingga yang terbentuk menunjukkan adanya flavonoid sedangkan warna kuning jingga menunjukkan adanya flavon, kalkon, dan auron (Hanani, 2015).

\section{Uji Alkaloid}

Ekstrak sebanyak 0,5 gram dilarutkan dengan dalam beberapa $\mathrm{mL}$ asam sulfat $2 \mathrm{~N}$ kemudian diuji dengan 2 pereaksi alkaloid yaitu pereaksi Dragendroff dan pereaksi Mayer. Hasil positif diperoleh bila terbentuk endapan merah hingga jingga dengan pereaksi Dragendroff dan endapan putih kekuningan dengan pereaksi Mayer (Hanani, 2015).

\section{Uji Saponin}

Ditimbang sampel ekstrak sebanyak 0,5 g dan dimasukan kedalam tabung reaksi, ditambahkan $10 \mathrm{~mL}$ air panas, didinginkan kemudian dikocok kuat-kuat selama 10 detik. Hasil positif ditandai dengan terbentuknya buih yang stabil selama tidak kurang dari 1 menit (Hanani, 2015).

\section{Uji Tanin}

Ekstrak 0,5 g ditambahkan dengan akuades panas lalu diaduk. Setelah dingin, larutan disentrifugasi. Cairan bagian atas dipisahkan dengan cara dekantasi, dan larutan digunakan sebagai larutan uji. Kehadiran tanin diuji dengan 2 cara:

a. Larutan uji ditambah $\mathrm{NaCl}$-gelatin (larutan gelatin $10 \%$ dalam larutan $\mathrm{NaCl}$ $10 \%$ dengan perbandingan 1:1). Hasil positif jika timbul endapan putih

b. Larutan Uji ditambahkan larutan $\mathrm{FeCl}_{3}$ $3 \%$. Hasil positif jika terjadi warna hijau biru hingga kehitaman (Hanani, 2015).

\section{Analisis Kadar Flavonoid \\ Penentuan Panjang Gelombang Maksimal Kuersetin}

Sebanyak $5 \mathrm{~mL}$ larutan standar kuersetin dalam etanol konsentrasi 100 ppm dimasukkan dalam labu ukur $50 \mathrm{~mL}$ dan ditambahkan $15 \mathrm{~mL}$ etanol 70, $1 \mathrm{~mL}$ $\mathrm{AlCl}_{3} 10 \%$, dan $1 \mathrm{~mL}$ natrium asetat $1 \mathrm{M}$ kemudian diencerkan dengan air suling sampai batas. Dikocok homogen lalu dibiarkan selama 30 menit. Absorbansinya diukur pada panjang gelombang 380-780 $\mathrm{nm}$ menggunakan spektrofotometer (Chang, et al. 2002).

\section{Penentuan Waktu Inkubasi Optimum}

Sebanyak $5 \mathrm{~mL}$ larutan standar kuersetin konsentrasi 100 ppm dimasukkan dalam labu ukur $50 \mathrm{~mL}$ ditambahkan 15 $\mathrm{mL}$ etanol $70 \%, 1 \mathrm{~mL} \mathrm{AlCl}_{3} 10 \%$, dan 1 $\mathrm{mL}$ natrium asetat $1 \mathrm{M}$ kemudian diencerkan dengan air suling sampai batas. Kemudian dihomogenkan dan diinkubasi pada suhu kamar. Serapan diukur pada panjang gelombang maksimum pada 5, 10, $15,20,25$, dan 30 menit sehingga didapat waktu optimum yang stabil (Chang, et al. 2002).

\section{Pembuatan Kurva Standar Kuersetin}

Dibuat deret standar kuersetin 2, 4, 6, 8, dan $10 \mathrm{ppm}$ dari larutan $100 \mathrm{ppm}$, sebanyak 1, 2, 3, 4, $5 \mathrm{~mL}$ larutan standar 100 ppm dipipet ke dalam labu ukur $50 \mathrm{~mL}$ kemudian ditambahkan $15 \mathrm{~mL}$ etanol 70\%, lalu ditambahkan $1 \mathrm{~mL} \mathrm{AlCl} 3$ 10\%, $1 \mathrm{~mL}$ 
natrium asetat $1 \mathrm{M}$ selanjutnya diencerkan dengan air suling sampai batas. Dikocok hingga homogen dan diinkubasi pada suhu kamar selama waktu optimumnya. Larutan diukur absorbannya dengan spektrofotometer UV-Vis pada panjang gelombang maksimum (Chang, et al. 2002).

Dari hasil pengukuran absorban dibuat kurva antara konsentrasi larutan standar kuersetin dengan nilai absorban yang diperoleh sehingga akan dihasilkan persamaan regresi linier $(y=b x+a)$. Persamaan regersi linier ini digunakan untuk menghitung kadar ekstrak (ppm) dengan memasukkan absorban ekstrak sebagai nilai Y ke dalam persamaan.

\section{Penentuan Kadar Flavonoid Ekstrak}

Sebanyak masing-masing $50 \mathrm{mg}$ ekstrak etanol $70 \%$ kulit bawang merah dari metode maserasi dan metode MAE dilarutkan dengan $50 \mathrm{~mL}$ etanol $70 \%$. Larutan dipipet $10 \mathrm{~mL}$ ke dalam labu ukur $50 \mathrm{~mL}$, dicampur dengan $15 \mathrm{~mL}$ etanol $70 \%$, ditambahkan $1 \mathrm{~mL} \mathrm{AlCl}_{3} 10 \%, 1 \mathrm{~mL}$ natrium asetat $1 \mathrm{M}$ dan air suling sampai batas. Larutan kemudian dipipet kembali sebanyak $10 \mathrm{~mL}$, di masukan ke dalam labu ukur 50mL ditambahkan air sampai batas dan dikocok hingga homogen. Larutan diinkubasi pada suhu kamar dan waktu optimum kemudian iukur serapannya dengan spektrofotometer UV-Vis pada panjang gelombang maksimum (Chang, et al. 2002).

\section{HASIL PENELITIAN \\ Karakteristik Simplisia Kulit Bawang Merah}

Serbuk simplisia kulit bawang merah memiliki warna merah kecoklatan, aromanya khas bau bawang merah. Rendemen simplisia yang diperoleh adalah sebesar $14,25 \%$.

\section{Kadar Air dan Kadar Abu Simplisia}

Hasil rata-rata pengujian kadar air serbuk simplisia kulit bawang merah sebesar $8.6 \%$ dan kadar air ekstrak kental kulit bawang merah sebesar 9.15\%. Hasil yang didapatkan sesuai dengan persyaratan secara umum kadar air simplisia tidak lebih dari 10\% (DepKes RI, 2000) dan kadar air ekstrak kental tidak lebih dari 22,2\% (DepKes RI, 2013). Penetapan kadar air perlu dilakukan untuk mengetahui besarnya kandungan air dalam suatu bahan. Kandungan air yang tinggi dapat menjadi media pertumbuhan mikroba, kapang dan mikroorganisme sehingga dapat menyebabkan perubahan kimia pada senyawa aktif (DepKes RI, 2000).

Hasil rata-rata pengujian kadar abu serbuk simplisia kulit bawang merah sebesar $8,56 \%$ dan kadar abu ekstrak kental kulit bawang merah sebesar $11.12 \%$. Hasil tersebut telah memenuhi syarat untuk kadar abu simplisia secara umun tidak boleh lebih dari 2\% sampai 14,1\% (DepKes RI, 1989) dan kadar abu ekstrak kental tidak lebih dar 3,9\% sampai 17,4\% (DepKes RI, 2013).

\section{Hasil Ekstrak Kulit Bawang Merah}

Rendemen yang didapatkan dari hasil ekstraksi metode maserasi sebesar $11,78 \%$ berat sampel sedangkan rendemen hasil ekstraksi metode MAE sebesar $10,85 \%$ berat sampel. Data-data ini menunjukan bahwa metode ekstraksi maserasi menghasilkan rendemen ekstrak yang lebih besar dibandingkan metode ekstraksi MAE. Hal ini mungkin terkait dengan lamanya waktu yang digunakan dalam proses ekstraksi maserasi $(2 \times 24$ jam) sehingga memungkinkan lebih banyak senyawa polar yang tertarik kedalam pelarut dan menghasilkan rendemen yang lebih besar daripada metode ekstraksi MAE (Prasetyo, 2015). Keunggulan proses ekstraksi metode MAE menurut Calinescu et al., (2001) adalah dapat meningkatkan efisiensi dan efektifitas ekstraksi bahan aktif bersifat 
polar dengan memberikan panas secara merata sehingga tidak merusak zat aktif yang terkandung dalam bahan, dan memerlukan waktu waktu yang singkat, cukup dalam hitungan menit.

\section{Hasil Uji Fitokimia}

Dari hasil uji fitokimia diketahui bahwa ekstrak etanol kulit bawang merah dari hasil ekstraksi dengan metode maserasi dan MAE mengandung positif mengandung senyawa flavonoid, alkaloid, saponin dan tanin seperti terlihat pada Tabel 1.

Tabel 1. Hasil Uji Fitokimia Ekstrak Kulit Bawang Merah

\begin{tabular}{ccc}
\hline Parameter Uji & $\begin{array}{c}\text { Ekstrak } \\
\text { maserasi }\end{array}$ & $\begin{array}{c}\text { Ekstrak } \\
\text { MAE }\end{array}$ \\
\cline { 2 - 3 } Saponin & + & + \\
\hline Flavonoid & + & + \\
Tanin & + & + \\
\hline Alkaloid & + & + \\
\hline
\end{tabular}

Hasil uji fitokimia terbukti sama dengan penelitian sebelumnya yang dilakukan oleh Rahayu, dan Nur (2015) yang menyatakan bahwa ekstrak kulit bawang merah mengandung alkaloid, flavonoid, saponin, dan tanin. Dari hasil penelitian Filomena (2007) diketahui juga bahwa bawang merah memiliki kandungan senyawa flavonoid seperti rutin dan kuersetin yang dapat digunakan sebagai antiinflamasi.

\section{Kadar Flavonoid Ekstrak Kulit Bawang Merah}

Pengukuran kadar flavonoid ekstrak kulit bawang merah dilakukan menggunakan Spektrofotometer UV-Vis pada panjang gelombang $435 \mathrm{~nm}$ dengan waktu inkubasi optimum 20 menit. Dari hasil pengukuran absorbansi didapatkan persamaan regresi linear $\mathrm{y}=0,0783 \mathrm{x}$ 0,0008 dengan nilai liniearitas $\left(\mathrm{R}^{2}\right)$ adalah
0,9993. Nilai linearitas menunjukkan kolerasi antara konsentrasi dan absorbansi yang dihasilkan. Semakin baik nilai linearitas (nilai $r$ sama dengan 1 atau mendekati 1) maka kolerasi juga semakin baik. Kadar flavonoid pada ekstrak kulit bawang merah dapat dilihat pada Tabel 2 .

\begin{tabular}{cc}
$\begin{array}{l}\text { Tabel 2. Kadar Flavonoid Ekstrak Kulit } \\
\text { Bawang Merah }\end{array}$ \\
\hline Sampel & $\begin{array}{c}\text { \% Kadar Flavonoid } \\
\text { Rata-rata }\end{array}$ \\
\hline Ekstrak maserasi & 14,9271 \\
Ekstrak MAE & 17,18375 \\
\hline
\end{tabular}

Data yang diperoleh menunjukan bahwa kadar flavonoid pada ekstrak kulit bawang merah yang didapatkan dengan metode maserasi sebesar $14,9271 \%$ dan kadar flavonoid pada ekstrak kulit bawang merah yang didapatkan dengan metode MAE sebesar 17,18375\%. Data ini menunjukan bahwa kadar flavonoid pada ekstrak kulit bawang merah dengan metode maserasi lebih kecil dibandingkan dengan metode MAE sehingga dapat diperkirakan ekstraksi metode MAE lebih banyak melarutkan zat aktif dibandingkan ekstraksi metode maserasi. Hasil penelitian yang dilakukan oleh Gregorio, et al., (2010) menunjukan bahwa kandungan senyawa flavonoid jenis flavonol pada bawang merah adalah sebesar 304,3 $\mathrm{mg} / \mathrm{kg}$. Perbedaan kadar flavonoid dari ekstrak kulit bawang merah dapat terjadi karena perbedaan pada metode pembuatan ekstrak, karena MAE merupakan gelombang elektromagnetik yang dapat menembus dinding sel simplisia dan mengeksitasi molekul air dan lemak secara merata sehingga ekstraksi lebij efektif terjadi tidak hanya pada permukaan sel saja. Gelombang elektromagnetik pada frekuensi MAE $2.500 \mathrm{MHz} \quad(2,5 \mathrm{GHz})$ diserap oleh air, lemak dan gula yang terdapat pada sel simplisia sehingga mengeksitasi atom-atom didalam sel dan menghasilkan panas. Proses ini bisa 
dilakukan sangat cepat sehingga penarikan senyawa pada kulit bawang merah lebih efektif dan efisien. Pada metode maserasi proses ekstraksi dilakukan dengan teknik perendaman pada suhu kamar, tidak menggunakan pemanasan sehingga kadar flavonoid yang dihasilkan lebih kecil dari kadar flavonoid dari ekstraksi metoda MAE.

\section{KESIMPULAN}

Kadar flavonoid ekstrak kulit bawang merah yang didapatkan dengan metode maserasi adalah sebesar 14,92\%, sedangkan kadar flavonoid ekstrak kulit bawang merah yang didapatkan dengan metode MAE adalah sebesar $17,18 \%$. Dapat disimpulkan bahwa metode MAE lebih efektif digunakan untuk mengekstrak flavonoid dari kulit bawang dibandingkan dengan metode maserasi.

\section{DAFTAR PUSTAKA}

Adi, L.T. 2007. Terapi Herbal Berdasarkan Golongan Darah. AgroMedia Pustaka. Jakarta. Hal. 116.

Arung, A., K. Shimizu, dan K. Kondo. 2006. Inhibitory effect of artocarpanone from Artocarfus heterohyllus on melanin biosynthesis. Biol. Pharm. Bull. 29 (9): 1966-1969.

Chang, C., M., Yang, W. Hand dan J. Chern. 2002. Estimation of total flavonoid content in propolis by two complementary colorimetric methods. J. Food Drug Anal. 10: 178-182.

DepKes RI. 1979. Materia Medika Indonesia. Jilid III. Direktorat Jenderal Pengawasan Obat Dan Makanan. Jakarta. 1979. Farmakope Indonesia. Jilid III. Direktorat Jenderal Pengawasan Obat Dan Makanan. Jakarta. Hal 510, 567, 338.
1986. Sedian Galenik. Direktorat Jenderal Pengawasan Obat Dan Makanan. Jakarta. . 2000. Parameter Standar Umum Ekstrak Tumbuhan Obat. Direktorat Jenderal Pengawasan Obat dan Makanan. Jakarta. 2013. Farmakope Herbal Indonesia. Direktorat Jenderal Pengawasan Obat Dan Makanan. Jakarta. Hal 110-111.

1989. Materia Medika Indonesia. Jilid V. Direktorat Jenderal Pengawasan Obat Dan Makanan. Jakarta. Hal 116-119.

Filomena, C., S. Silvio, M., Mariangela, M., Federica, A.S., Giancarlo, U. Dimitar, T. Aurelia, M. Francesco, D.L. Roberto. 2008. In vivo antiinflammatory and in vitro antioxidant activities of mediterranean dietary plants. Journal of Ethnopharmaclogy. 116: 144-151.

Gregorio, R.M.P., S.G.F. Mercedes, S.G. Jesus, S.R. Ana, P.F.A. Domingos. 2010. Identification and quantification of flavonoid in traditional cultivars of red and white onion at harvest. Journal of Food Composition and Analysis. 23: 592598.

Gulsen, A., D.P. Makris, P., Kefalas. 2007. Biomimetic oxidation of quercetin: isolation of a naturally occurring quercetin heterodimer and evaluation of its in vitro antioxidant properties. Food Res. Int. 40: 7 - 14.

Harborne, J.B. 1996. Metode Fitokimia: Penuntun Cara Modern Menganalisa Tumbuhan. Terbitan Kedua. ITB. Bandung. Hal: 123-129.

Hanani, E. 2015. Analisis Fitokimia. Buku Kedokteran EGC. Jakarta. Hal: 8556.

Handayani D., Mun'im, A., A. S. Ranti. 2014. Optimation of green tea waste extraction using microwave assisted 
extraction to yield green tea extract. Traditional Medicine Journal. 19(1): 29-35.

Jaelani. 2007. Khasiat Bawang Merah. Kanisius. Yogyakarta. Hal. 94.

Jain, T., V. Jain, R. Pandey, A. Vyas, S. dan S. Shukla. 2009. Microwave Assisted Extraction for Phytoconstituents, An Overview. Asian Journal Research Chemistry. 2.

Markham, K.R. 1988. Cara Mengidentifikasi Flavonoid. Diterjemahkan oleh Padmawinata. ITB. Bandung.

Marliana, S. D., V. Suryanti, S. Suyono. 2005. Skrining fitokimia dan analisis kromatografi lapis tipis komponen kimia buah labu siam (Sechium edule Jacq. Swartz.) dalam ekstrak etanol. Biofarmasi 3 (1): 26-31.

Prakash, D., G. Upadhyay, B.N. Singh, H.B. Singh. 2007. Antioxidant and free radical-scavenging activities of seeds and agri-wastes of some varieties of soybean (Glycine $\max$ ). Food Chem. 104: 783 - 790.

Rahayu, E., B. Nur. 2015. Mengenal Varietas Unggul dan Cara Budidaya Secara Kontinu Bawang Merah. Penebar Swadaya. Jakarta. Hal: 1.

Rohyami, Y. 2008. Penentuan kandungan flavonoid dari ekstrak metanol daging buah mahkota dewa (Phaleria macrocarpa Scheff Boerl). Jurnal Logika. 5(1): 1-16.

Prasetyo, H. 2015. Ekstraksi senyawa antioksidan kulit buah kopi : kajian jenis kopi dan lama maserasi.
Skripsi. Fakultas Teknologi Pertanian. Universitas Jember. Jawa Timur.

Quan, P. T., T.V. Han, H. Nguyen, X. Nguyen dT.N. Tuyen. 2006. Micrrowave assisted extraction of polyphenols from fresh tea shoot. Science \& Technology Development. 9 (8): 69 -75.

Rompas, R.A., H.J. Edy, A. Yudistira. 2012. Isolasi dan identifikasi flavonoid dalam daun lamun (Syringodium isoetifolium). Pharmacon. 1(2): 59-62.

Soebagio. B., T. Rusdiana, K. Khairudin. 2007. Pembuatan gel dengan aqupec Hv-505 dari ekstrak umbi bawang merah (Allium cepa L.) sebagai. antioksidan. Seminar Penelitian Dosen Fakultas Farmasi. Universitas Padjadjaran. Bandung

Sugiarto, A., T.D. Putera. 2008. Buku Pintar Tanaman Obat: 431 Jenis Tanaman Penggempur Aneka Penyakit. PT Agromedia Pustaka. Jakarta.

Sangi, M., R.J.R. Max, E.I.S Herni, M.A.M. Veronica. 2008. Analisis Fitokimia Tumbuhan Obat Di Kabupaten Minahasa Utara. Chemistry Progress. 1(1): 49-52.

Utami, P., L. Mardiana. 2013. Umbi Ajaib Tumpas Penyakit. Penebar Swadaya. Jakarta. Hal: 87.

Umar, F. 2008. Optimasi ekstraksi flavonoid total daun jati belanda. Skripsi. Fakultas Matematika dan Ilmu Pengetahuan Alam Institut Pertannian Bogor. 